\title{
Development of NCOVID-19 Colloidal Gold Immunochromatographic Test Strip
}

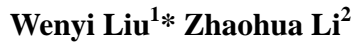 \\ ${ }^{1}$ Pudong Foreign Language School, Shanghai 201203, China. E-mail: 156420698@qq.com \\ ${ }^{2}$ Institute of Botany, the Chinese Academy of Sciences, Beijing 100101, China.
}

Abstract: Purpose: To establish a fast, simple and accurate method and immunoassay test card for the detection of new coronavirus (nCOVID-19) antigen. Methods: In this study, colloidal gold immunochromatography technology was used to detect nCOVID-19 virus antigens through the sandwich method. At the same time, the preparation plan of colloidal gold was improved, and the application of rapid immune-diagnosis technology in other fields was developed. In this study, purified recombinant nCOVID-19 nucleocapsid protein is used as the antigen to prepare murine monoclonal antibodies. The BN02 antibody produced by the mouse is used as the detection antibody to couple with colloidal gold, forming a gold-labeled complex probe. BN9m1 is used as the coating antibody for the C-line, and ProA is used for the T-line. The polymerization of colloidal gold particles enables us to detect the new coronavirus antigen's appearance. Thus an in vitro rapid detection kit for virus detection can be made. Results: The positive detection rate of the antigen quality control serum with this colloidal gold reagent was $100 \%$. The specificity was $100 \%$, and the sensitivity was 1ng/ml. Conclusion: The nCOVID-19 antigen detection reagent (colloidal gold method) developed in this research has high specificity and sensitivity, and can be used in conjunction with nucleic acid detection. As a means of detecting nCOVID-19, it can achieve qualitative and rapid screening of samples with advantage such as accuracy, repeatability, and low cost.

Keywords: NCOVID-19; Colloidal Gold Immunochromatographic Stripe; Nucleocapsid Protein

\section{Experimental equipment and materials}

\subsection{Experimental equipment}

Ultraviolet spectrophotometer, PCR instrument, electronic balance (accuracy to two decimal places), pipette, ultra-clean workbench, portable pressure steam sterilizer, shaking shaker, constant temperature water bath, electrophoresis instrument, ultraviolet analyzer.

\subsection{Experimental materials}

Solid $\mathrm{NaCl}$, yeast powder, peptone, agar powder,
$\mathrm{Na}_{2} \mathrm{HPO} 4, \mathrm{NaH}_{2} \mathrm{PO} 4$, Mix solution, DNA template, DNA upper and lower primers, agarose, 1XTAE, fluorescent green dye, solution P1 (containing RNaseA), solution P2 (main ingredients $\mathrm{NaOH}$, SDS), solution P3 containing acidic substances, washing solution WB, casein, nitrocellulose membrane, filters and membranes, glass cellulose membrane, absorbent pad, stickers, pad, 2\% BSA, 2.5\% sucrose, 1\% spit Temperature-20, 0.3\% PVPk30, $0.02 \%$ sodium azide, $1 \%$ trisodium citrate, potassium carbonate, sodium chloride, chloroauric acid tetrahydrate, Tris-base, HCI, glass fiber filter paper, water-absorbing material membrane, 0.1 \% PEG20000, 0.5\% BSA, 0.1\%

\footnotetext{
Copyright (C) 2021 Wenyi Liu et al.

doi: 10.18686/aem.v10i1.182

This is an open-access article distributed under the terms of the Creative Commons Attribution Non-Commercial License (http://creativecommons.org/licenses/by-nc/4.0/), which permits unrestricted non-commercial use, distribution, and reproduction in any medium, provided the original work is properly cited.
} 
$\mathrm{NaN}_{3} \mathrm{NaHCO}_{3}, \mathrm{KH}_{2} \mathrm{PO} 4, \mathrm{KCl}$, borax, boric acid, 0.22 micron filter membrane ${ }^{[1]}$.

\section{Research methods and proce- dures}

\subsection{Preparation of antigen}

\subsubsection{PCR}

Use $2 \mathrm{X}$ mix (containing $\mathrm{Mg}^{2+}$, Taq enzyme, DNTP, etc.), 25 microliters, 22 microliters of water, 1 microliter of template, and 1 microliter of upstream and down-stream primers to configure a 50 microliter reaction system into the PCR tube. Set the lid temperature to $105^{\circ} \mathrm{C}$. Pre-denaturation $95^{\circ} \mathrm{C}$ for 3 min. Denaturation at $98^{\circ} \mathrm{C}$ for $10 \mathrm{~s}$; annealing at $68^{\circ} \mathrm{C}$ for $20 \mathrm{~s}$; extension at $72^{\circ} \mathrm{C}$ for $45 \mathrm{~s}$. A total of 39 cycles were cycled from denaturation to extension, and the annealing temperature was reduced by $0.5^{\circ} \mathrm{C}$ for each cycle. After the end of the cycle, it was set to continue to extend at $72^{\circ} \mathrm{C}$ for 5 minutes to ensure that all fragments were fully extended. Finally, set a storage temperature of $4^{\circ} \mathrm{C}$ to prevent DNA degradation.

\subsubsection{Agarose gel electrophoresis}

Prepare a $1 \%$ agarose solution, pour it into the identification glue tank and the recovery glue tank respectively, insert the comb, and wait for about 30 minutes for the gel to solidify before taking it out. Pour $1 \mathrm{X}$ TAE buffer into the electrophoresis tank, and use a pipette to pipette the PCR amplification solution and Marker for spotting. Stop the electrophoresis when the Marker moves to the middle of the gel. An ultraviolet analyzer was used to measure the spectrum. Cut the gel where the target DNA is located, add GDP sol agent, and centrifuge for DNA gel recovery.

\subsubsection{Preparation of LB medium}

Configure $1 \mathrm{~L}$ LB liquid medium containing 1\% peptone, $0.5 \%$ yeast, and $1 \% \mathrm{NaCl}$. The solid medium was added $1.5 \%$ to $2 \%$ agar on this basis. After the addition was dissolved and its $\mathrm{pH}$ was adjusted to 7.0, it was put into a portable pressure steam sterilizer for sterilization at $121^{\circ} \mathrm{C}$ for 20 minutes. After the end, the solution was cooled to 60 degrees, and kanamycin was added in the ratio of kanamycin: culture solution $=1: 1000$ and mixed. Pour the warm solid culture medium into a petri dish. The solid culture medium in each petri dish was about $10 \mathrm{ml}$. This step was completed on the ultra-clean workbench.

\subsubsection{Conversion}

Use restriction endonuclease to cut the DNA and clone vector obtained by PCR, and use T4 ligase and its buffer to connect the two in a connect meter set at $16^{\circ} \mathrm{C}$. This process took 2 hours. After completion, mix the bacterial liquid with the competent cells of E. coli and bath in ice for 30 minutes to allow the surface of $\mathrm{E}$. coli to form liquid crystals that can adsorb DNA. Then heat-shock the competent cells of E. coli at $42^{\circ} \mathrm{C}$ for $90 \mathrm{~s}$ repeatedly to make the DNA enter $\mathrm{E}$. coli, and then ice bath for $2 \mathrm{~min}$. Finally, the bacteria solution was coated on the plate and placed in a biochemical incubator at $37^{\circ} \mathrm{C}$ for 12 hours to allow E. coli to form monoclonal colonies.

\subsubsection{Plasmid extraction}

Mainly use alkaline lysis method for plasmid extraction of Escherichia coli. Put the bacterial solution in a centrifuge, at $13000 \mathrm{r} / \mathrm{min}$ for $1 \mathrm{~min}$, and remove the supernatant after taking it out. P1 was added to resuspend the bacteria, then add P2 (containing alkaline substances, such as $\mathrm{NaOH}$ and SDS), shake and mix, and then add P3 (containing acidic substances) to refold the plasmid. The supernatant was extracted and put into the filter column and then centrifuged at $12000 \mathrm{r} / \mathrm{min}$ for $30 \mathrm{~s}$. Pour out the lower clear liquid, rinse twice and centrifuge twice. Let dry. The plasmid DNA on the filter column is recovered. Then the DNA is sequenced.

\subsection{Antigen identification}

\subsubsection{Transfer of Escherichia coli}

After confirming the successful implantation of the target gene, the colony of Escherichia coli amplified on the liquid medium was transferred to the LB liquid medium. Place it on an orbital shaker and shake at room temperature for 24 hours to supply oxygen to E. coli to survive and proliferate in large numbers.

\subsubsection{SDS-PAGE}

Prepare $\quad 30 \% \quad$ polyacrylamide solution, 5XTris-glycine electrophoresis buffer, 5XSDS-PAGE loading buffer, Coomassie brilliant blue R-250 staining solution, and Coomassie brilliant blue staining decolorizing solution.

Configure $10 \mathrm{ml}$ separating gel (see Table 1 for components) and 10ml concentrated gel (see Table 2 for components). 
Table 1. $10 \mathrm{ml}$ separating gel

\begin{tabular}{|l|l|}
\hline Composition & Volume(mL) \\
\hline $\mathrm{ddH}_{2} \mathrm{O}$ & 3.3 \\
\hline $30 \%$ polyacrylamide & 4.0 \\
\hline $1.5 \mathrm{M}$ Tris-HCl(pH8.8) & 2.5 \\
\hline $10 \%$ SDS & 0.1 \\
\hline $10 \%$ Ammonium persulfate & 0.1 \\
\hline TEMED & 0.004 \\
\hline
\end{tabular}

Table 2. 10ml concentrated gel

\begin{tabular}{|l|l|}
\hline Composition & Volume(mL) \\
\hline $\mathrm{ddH}_{2} \mathrm{O}$ & 6.8 \\
\hline $30 \%$ polyacrylamide & 1.7 \\
\hline $1.5 \mathrm{M}$ Tris-HCl(pH8.8) & 1.25 \\
\hline $10 \%$ SDS & 0.1 \\
\hline $10 \%$ Ammonium persulfate & 0.1 \\
\hline TEMED & 0.01 \\
\hline
\end{tabular}

First take $4 \mathrm{ml}$ of separating glue and add it to the glue maker, then add distilled water on top. Let it stand for 20 minutes, and then the separating glue would solidify. Pour out the distilled water, add the concentrated glue until the liquid level is flush with the top of the glass plate, insert the comb, and concentrate the glue after 5-10 minutes. After solidification, remove the glass plate, pull out the comb horizontally, and insert the remaining part into the electrophoresis tank.

Dilute 5X Tris-Glycine running buffer five times into the electrophoresis tank, pass the sample hole, and then start spotting (protein and marker). After spotting, set the parameters of the electrophoresis instrument to $120 \mathrm{~V}, 90 \mathrm{~mA}$, and power on to start electrophoresis. Stop the electrophoresis when the protein marker runs to the bottom of the gel.

The gel was taken out in water, stained with Coomassie Brilliant Blue R-250 stain, and then decolorized with Coomassie Brilliant Blue Decolorizing Solution, and the protein bands were compared with the Marker ${ }^{[2]}$.

\subsection{Preparation of colloidal gold}

This experiment used the trisodium citrate reduction method for the preparation of colloidal gold. First, prepare a $0.1 \%$ chloroauric acid solution, dilute $10 \mathrm{ml}$ ten times with a 0.22 micron filter membrane, and place it on an induction cooker at $1200^{\circ} \mathrm{C}$ and heat it to boil. Start adding the prepared $1 \%$ trisodium citrate solution and adjust the temperature to $1000^{\circ} \mathrm{C}$. When the solution started to show a pale pink color, after dripping $2 \mathrm{ml}$ of trisodium citrate solution, stop dripping the trisodium citrate solution and adjust the temperature to $800^{\circ} \mathrm{C}$. During this period, the solution was continuously stirred to make it evenly mixed, and the color of the solution changed from light pink-pink-dark pink-purple red. Continue heating for 11 minutes and turn off the power of the induction cooker, and took it off after the purple-red translucent colloidal gold had cooled. The Tyndall effect can be used to verify its quality. After the preparation, the colloidal gold was put into a centrifuge tube and stored under refrigeration at $4^{\circ} \mathrm{C}$.

\subsection{Preparation of protein-colloidal gold complex}

\subsubsection{Preparation of reagents used}

(1) $0.1 \mathrm{~mol} / \mathrm{L} \mathrm{Na}_{2} \mathrm{CO}_{3}$

Weigh $1.06 \mathrm{~g}$ of $\mathrm{Na}_{2} \mathrm{CO}_{3}$, add $\mathrm{ddH}_{2} \mathrm{O}$, and dilute to $100 \mathrm{~mL}$.

(2) Preparation of $\quad \mathrm{pH} \quad 7.4 \quad 0.01 \mathrm{~mol} / \mathrm{L}$ phate buffer (PB)

A liquid $0.2 \mathrm{~mol} / \mathrm{L}$ Na2HP04 B liquid $0.2 \mathrm{~mol} / \mathrm{L}$ $\mathrm{NaH}_{2} \mathrm{PO}_{4}$

Take $81.0 \mathrm{ml}$ of A solution and add $19 \mathrm{ml}$ of B solution, then add $1900 \mathrm{ml}$ ddH20 and $17 \mathrm{~g} \mathrm{NaCl}$, which is a pH7.4 0.01mol/L PBS solution.

(3) Preparation of $10 \% \mathrm{NaCl}$

Weigh $10 \mathrm{~g}$ of $\mathrm{NaCl}$, measure $\mathrm{ddH}_{2} \mathrm{O}$, and dilute to $100 \mathrm{~mL}$.

(4) Preparation of $10 \%$ BSA

Weigh $5 \mathrm{~g}$ of BSA, and dilute $\mathrm{ddH}_{2} \mathrm{O}$ to $50 \mathrm{~mL}$.

(5) Preparation of resuspension liquid I

Weigh BSA 2g, Tris-Base 0.121g, measure $\mathrm{ddH}_{2} \mathrm{O}$ and dilute to $100 \mathrm{~mL}$.

(6) Preparation of resuspension liquid II

Weigh $1 \mathrm{~g}$ of BSA, $0.121 \mathrm{~g}$ of Tris-Base, $1 \mathrm{~g}$ of sucrose, measure $0.5 \mathrm{~mL}$ Tween-20, and measure $\mathrm{ddH}_{2} \mathrm{O}$ to a constant volume of $100 \mathrm{~mL}$

(7) Preparation of physiological saline

Weigh $0.85 \mathrm{~g}$ of $\mathrm{NaCl}$, measure $\mathrm{ddH}_{2} \mathrm{O}$ and dilute to $100 \mathrm{~mL}$.

\subsubsection{Calibration of minimum protein con- tent by visual inspection}

Take $10 \mathrm{~mL}$ of colloidal gold and adjust the $\mathrm{pH}$ to 8.2 with $0.1 \mathrm{~mol} / \mathrm{L} \mathrm{Na}_{2} \mathrm{CO}_{3}$.

Take a 96-well plate, add 100 microliters of the 
above colloidal gold to two rows of wells, add six holes in each row, and add 5 microliters of water, 4 microliters of water and 1 microliter of antibody to the first four wells (concentration $1 \mathrm{Mg} / \mu \mathrm{l}$ ), $3 \mu \mathrm{l}$ water and $2 \mu \mathrm{l}$ antibody and $5 \mu$ antibody. The last two wells are negative control wells and no antibody is added. Mix and let it stand at room temperature for 10-15 minutes. Then add $10 \mathrm{uL}$ of $10 \% \mathrm{NaCl}$ solution to the first five wells of each column. Mix and leave at room temperature for 10 minutes. Observe the color change of colloidal gold and record the lowest antibody concentration that remains red. After 2 hours at room temperature, record the lowest antibody concentration that remains red.

\subsubsection{Preparation of IgG-Gold}

Take $1 \mathrm{~mL}$ of colloidal gold solution with $\mathrm{pH}=8.2$ ( $\mathrm{pH}$ has been adjusted), and add 50 micrograms of antibody protein dropwise. Mix well and place at room temperature for 15 minutes. Then add $100 \mu \mathrm{l}$ of $10 \%$ BSA to the colloidal gold solution so that the final concentration of BSA in the colloidal gold solution is $1 \%$. After standing at room temperature for 15 minutes, centrifuge at 10,000 rpm for 20 minutes, and gently aspirate the supernatant. Suspend with $1 \mathrm{~mL}$ of Resuspension I, and centrifuge at $4^{\circ} \mathrm{C}$ at $10,000 \mathrm{rpm}$ for $30 \mathrm{~min}$. Gently aspirate the supernatant, suspend the pellet with $20 \mu \mathrm{l}$ of Resuspension Solution II, and store at $4^{\circ} \mathrm{C}$ for later use.

\section{Results and analysis}

\subsection{Results of agarose gel electrophoresis}

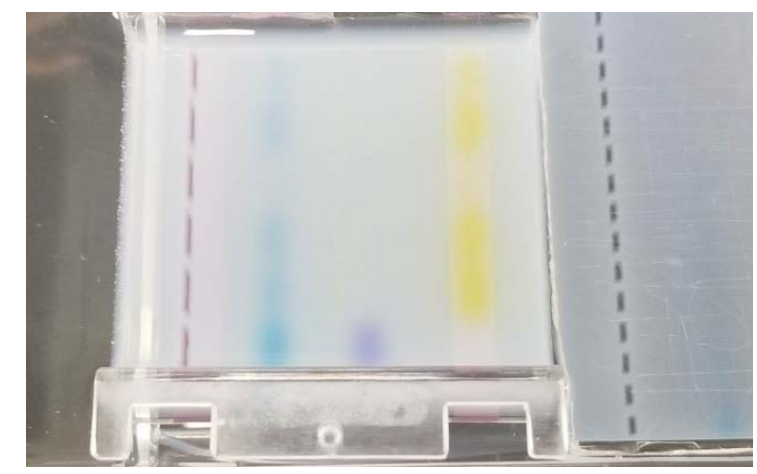

Figure 1. Test result (1).

The results of agarose gel electrophoresis measured under the UV instrument are shown in the figure. Compared with the marker, it can be seen that the DNA fragments are between 500-750bp, indicating that the target
DNA fragments amplified by PCR are pure and correct. After the gel is recovered, the result of DNA electrophoresis on the recovered gel is shown on the right. The DNA electrophoresis path can be clearly seen, and the electrophoresis result is excellent.

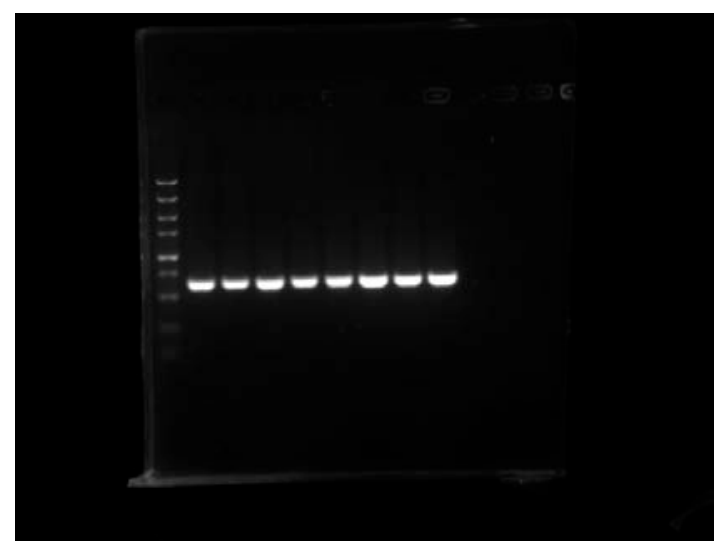

Figure 2. Test result (2).

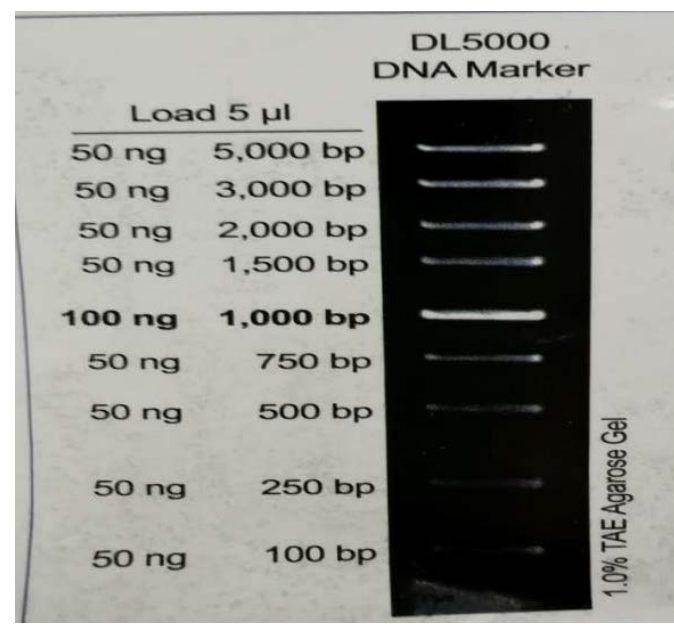

Figure 3. Test result (3).

\subsection{SDS-PAGE results}

The protein in the figure is relatively aggregated, has no tailing phenomenon, and has high purity, which can be used for further coupling.

\subsection{Preparation and quality monitoring re- sults of colloidal gold}

The prepared colloidal gold solution was transparent and clarified wine-red color, with gold particles floating on the solution. Obvious light movement paths can be seen through the penetration and irradiation of the laser pointer, and it can be seen that the quality of colloidal gold is good. 


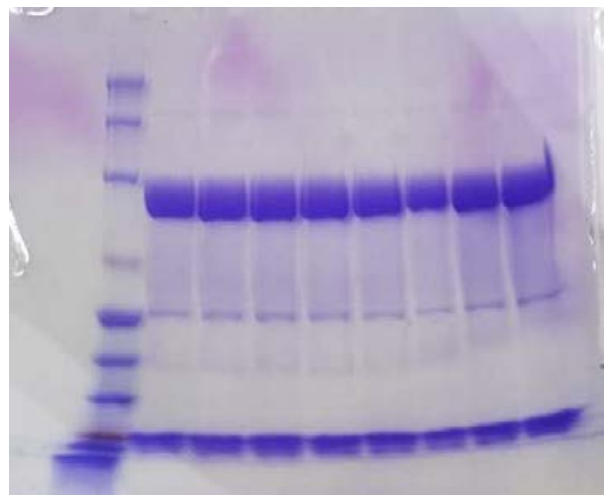

Figure 4. Test result (4).

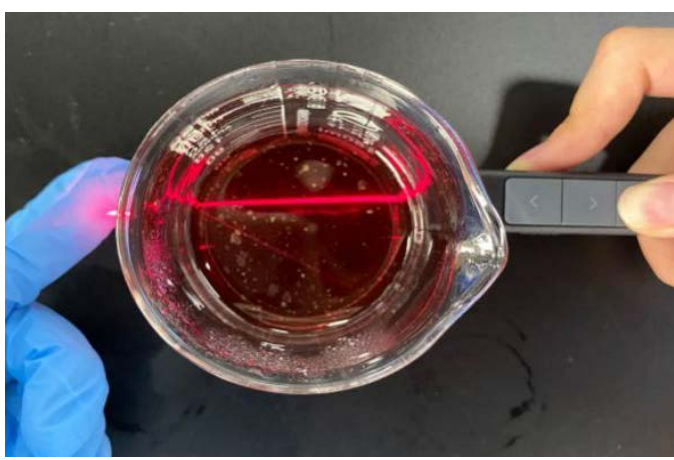

Figure 5. Test result (5).

\subsection{Measurement results of minimum pro- tein concentration}

In this experiment, the protection test of colloidal gold with different concentration gradients of protein in salt solution is shown in the figure. It is found that $0-2$ $\mu \mathrm{g} / \mathrm{ml}$ cannot stabilize the colloidal gold, and the coagulation phenomenon from red to blue appears, from 5 $\mu \mathrm{g} / \mathrm{ml}$. Starting from milliliter, the color of colloidal gold is basically stable and consistent, and the optimal protein concentration is $5 \mu \mathrm{g} / \mathrm{ml}$.

Table 3. Sample and absorbancy

\begin{tabular}{|l|l|}
\hline Sample & Absorbancy \\
\hline Water & $0.000 \mathrm{~A}$ \\
\hline 0 & $0.003 \mathrm{~A}$ \\
\hline 1 & $0.006 \mathrm{~A}$ \\
\hline 2 & $0.009 \mathrm{~A}$ \\
\hline 5 & $0.029 \mathrm{~A}$ \\
\hline$+\mathrm{NaCl}$ & $0.006 \mathrm{~A}$ \\
\hline$-\mathrm{NaCl}$ & $0.044 \mathrm{~A}$ \\
\hline
\end{tabular}

\section{Summary of the deficiencies of the experiment and future pro-}

spects

\subsection{Improvement of experimental proce- dures}

In the preparation of 2.3 colloidal gold, we used manual stirring throughout the process, which could not reach the ideal stirring rate of $300 \mathrm{rpm}^{[3]}$. We hope that we can change to magnetic stirring in subsequent improvements, so that the prepared colloidal gold may be even better. For high quality, the particle size is more uniform. In addition, the surface of the colloidal gold we made still has oily suspended matter, which requires more filtration to make it more pure. And we need colloidal gold prepared in cold storage.

When determining the minimum antibody content in 2.4.2, we thought that the set concentration gradient was not enough, and the minimum antibody content should be greater than $0.05 \mu \mathrm{g} / \mu \mathrm{l}$. However, due to material limitations, we could not continue to subdivide. In our subsequent experiments, A concentration gradient with a smaller minimum division value and a larger maximum measurement value should be set. For example, the difference in antibody content in adjacent wells is $0.005 \mu \mathrm{g} / \mu \mathrm{l}$, and the highest antibody content is at 0.1 $\mu \mathrm{g} / \mu \mathrm{l}$. We think this is the determination. The value that comes out is more reasonable and more accurate.

\subsection{Innovations and future prospects}

This kit is an in vitro rapid detection kit for the new coronavirus. Although similar kits have appeared on the market, the indirect method for IgM antibody detection is adopted $^{[4]}$. This kit uses immunochromatographic detection of IgG antibodies, which is the first innovation. As the human body's first response antibody, IgG has a faster response rate than IgM and a higher detection rate. It is more suitable for testing patients who have just been infected with nCOVID-19.

However, as a rapid detection kit, this product still has the disadvantage of relying on the antigen concentration in the sample. When the concentration is less than $10 \mathrm{ng}$, the product will still show negative, but the tester may still have new coronary pneumonia. Therefore, we hope to add a water-absorbent pad between the sample pad and the colloidal gold pad, with a layer of permeable membrane on it, so that water can penetrate but the antigen cannot, thus concentrating the antigen to improve 
accuracy. In order to ensure that the chromatography can still be performed, it is necessary to design the amount of water that the absorbent pad can absorb and the amount of sample dripping.

Fast mass production and low price will be the advantages of this product. At the same time, its fast detection speed and high sensitivity will also become major advantages to improve market competitiveness.

At the same time, we believe that colloidal gold technology should not only be limited to virus detection, but can also be applied to pesticide residue detection, water pollution monitoring, etc., but all this still requires follow-up research and observation. We hope that this emerging labeling method can be applied to a wider field.

\section{References}

1. Hou N, Chen Y, Ren J, et al. Origin and detection methods of SARS-CoV-2. Drug Evaluation Research 2020; 43(4): 620-623. doi:10.7501/j.issn.1674-6376.2020.04.006.

2. Liu Y, Li J, Zhang L, et al. Improvement and optimization of preparation technology of colloidal gold. Food and Fermentation Industry 2015; 41(11): 110 114. doi:10.13995/j.cnki.11-1802/ts.201511020.

3. Xin H, Xiong X, Liang J, et al. Preparation of colloidal gold used in immunoassay and control of particle size. Chinese Journal of Rare Metals, 2005; 29 (4): 471-474. doi:10.13373/j.cnki.cjrm.2005.04.021.

4. New Coronavirus IgM Antibody Rapid Detection Kit [Internet]. Available from http://wz.premedglobal.com/en/m/view.php?aid=112 